NOTA CIENTÍFICA

\title{
MATURAÇÃO DOS FRUTOS DE QUATRO CULTIVARES DE UVAS MUSCADÍNIAS EM PINHAIS, PR
}

\section{FRUIT MATURATION IN FOUR MUSCADINE GRAPE CULTIVARS IN PINHAIS, $P R$}

\author{
Adriana De Toni SACHI \\ Luiz Antonio BIASI ${ }^{2}$
}

\begin{abstract}
RESUMO
O objetivo deste trabalho foi avaliar a evolução da maturação dos frutos de quatro cultivares de uvas muscadínias para determinar o ponto ideal de colheita. O trabalho foi realizado durante o período de março a abril de 2007, com duas cultivares brancas (Dixie e Roanoke) e duas cultivares tintas (Bontiful e Regale) do setor de Fruticultura da Estação Experimental Cangüiri, da Universidade Federal do Paraná, em Pinhais (PR), Brasil. O delineamento experimental foi inteiramente casualizado com cinco repetições, formadas por cinco cachos cada. Os cachos foram coletados semanalmente a partir do início da maturação totalizando sete avaliações. As variáveis analisadas foram teor de sólidos solúveis (SS), pH, acidez titulável (AT) e relação SS/AT. Verificou-se que a cultivar Dixie apresentou o maior teor de sólidos solúveis, maior pH, maior relação SS/AT e menor acidez durante a maturação dos frutos. As cultivares tintas apresentaram menor relação SS/AT do que as brancas. As cultivares Dixie e Bontiful foram mais precoces, sendo indicada a colheita 215 dias após a brotação e as cultivares Regale e Roanoke podem ser colhidas no final do mês de abril, com 229 dias após a brotação.
\end{abstract}

Palavras-chave: Vitis rotundifolia; sólidos solúveis; acidez; ponto de colheita.

\begin{abstract}
The objective of this work was to evaluate fruit maturation of four muscatine grape cultivars to determine the harvest date for these cultivars. The experiment was performed from March to April 2007 at the Fruit Crop Section of the Canguiri Experimental Station, Federal University of Parana, in Pinhais, PR, Brazil. Grape berry maturation of two white (Dixie and Roanoke) and two red (Bontiful and Regale) muscadine cultivars were monitored from veraison to ripe berry. Five replications of five randomly selected clusters from each cultivar were collected once a week, for seven weeks. The analyzed variables were soluble solids (SS), $\mathrm{pH}$, titratable acidity (TA) and SS/TA ratio. Dixie presented the highest SS, $\mathrm{pH}$ and SS/TA ratio and the lowest TA of the four tested cultivars during the whole maturation process. The red cultivars presented lower SS/TA ratio than the white ones. Dixie and Bontiful were the most precocious cultivars, reaching the harvest point 215 days after bud break. Regale and Roanoke could be harvested at end of April, 229 days after bud break.

Key-words: Vitis rotundifolia; soluble solids; acidity; harvest date.
\end{abstract}

\footnotetext{
Aluna de Graduação da Universidade Federal do Paraná. E-mail: detonadri@yahoo.com.

${ }^{2}$ Engenheiro Agrônomo, Dr., Professor Associado, Departamento de Fitotecnia e Fitossanitarismo, Setor de Ciências Agrárias, UFPR. Caixa Postal 19061. 81531-990. Curitiba-PR. E-mail: biasi@ufpr.br. Bolsista de Produtividade em Pesquisa do CNPq. Autor para correspondência.
} 


\section{INTRODUÇÃO}

A fase de maturação das uvas abrange o período que vai da mudança da cor até a colheita. Pode durar de 30 a 70 dias, dependendo da cultivar e da região de cultivo. A sobrematuração começa a partir do momento em que não há mais síntese significativa de açúcares nem decréscimo apreciável de acidez. As flutuações nos teores de açúcares e ácidos nessa fase devem-se a fenômenos de diluição e dessecação das bagas, ocasionados por ocorrências de chuvas ou por períodos de seca, respectivamente (MOTA, et al., 2006).

A uva muscadínia (Vitis rotundifolia Michx.) é nativa do sudeste dos Estados Unidos, sendo a primeira espécie de uva americana a ser cultivada. São caracterizadas por serem pouco açucaradas, muitos cachos por planta e poucas bagas por cacho, formação de uma zona de abscisão entre a fruta e a ráquis, casca não estriada e aderente, lenho duro e maturação escalonada (HIDALGO, 1993; SOUSA, 1996).

Embora as cultivares desta espécie apresentem alguns problemas agronômicos como maturação desuniforme, os frutos podem ser empregados na elaboração de suco, vinho e geléia, além de serem indicados para consumo in natura (BOTTON et al., 2004). A videira muscadínia é praticamente imune às moléstias mais comuns, bem como às pragas (incluindo filoxera e pérolada-terra). No entanto, as cultivares dessa espécie são de difícil propagação e não há um mercado consumidor estabelecido para as mesmas (GIOVANNINI, 2001). São comercialmente importantes no sudeste dos Estados Unidos, onde são conhecidas como pequenas frutas, e atualmente estão aumentando em importância no Brasil, devido às suas características de adaptação a sistemas de produção orgânica e às suas propriedades nutracêuticas (HOFFMANN e SEBBEN, 2003). As uvas muscadínias possuem antocianinas e compostos fenólicos, como o ácido elágico e resveratrol, que conferem importante propriedade antioxidante (PASTRANA-BONILLA et al., 2003).

Diferentes critérios são utilizados para a determinação do ponto ideal de colheita da uva, pois o estágio da maturação no qual é colhida condiciona a qualidade e o tipo dos produtos dela obtidos.

A uva é uma fruta não climatérica, com baixa taxa respiratória, não evoluindo em maturação após a colheita (MANICA e POMMER, 2006). Desta forma, os teores de açúcares e de ácidos permanecem inalterados após esta fase. Portanto, é de fundamental importância que a colheita seja realizada no ponto ideal de maturação, pois as uvas cessam este processo após terem sido colhidas. A uva convenientemente monitorada ao longo da maturação será colhida no momento mais adequado à máxima expressão do seu potencial de qualidade em determinada safra ou região (GUERRA, 2003).
Assim, se não for realizado 0 acompanhamento da maturação complementado por avaliações sensoriais e químicas constantes da uva, não haverá informações suficientemente precisas sobre o estádio de maturação que permitam escolher com precisão a data de colheita.

O objetivo deste trabalho foi analisar a evolução da maturação dos frutos de quatro cultivares de uvas muscadínias para determinar o ponto ideal de colheita.

\section{MATERIAL E MÉTODOS}

Os cachos foram coletados nos meses de março a abril de 2007, da coleção de cultivares de Vitis rotundifolia no setor de Fruticultura da Estação Experimental Cangüiri, da Universidade Federal do Paraná (UFPR), em Pinhais-PR. A região pela classificação de Köeppen, apresenta clima do tipo Cfb.

As cultivares utilizadas foram Bontiful, Regale (uvas tintas), Dixie e Roanoke (uvas brancas). O delineamento experimental utilizado foi o inteiramente casualizado com cinco repetições, sendo que cada cultivar constituiu um tratamento e cada unidade experimental foi formada por cinco cachos de uva.

A colheita foi manual, fazendo-se uma seleção e toalete dos cachos, descartando-se as bagas que eventualmente apresentavam algum tipo de defeito ou grande desuniformidade na maturação, como bagas ainda muito pequenas e verdes.

As avaliações, no total de sete, foram realizadas semanalmente após a mudança de cor, iniciando aos 187 dias após a brotação. Os cachos foram levados ao laboratório, onde foram esmagados com pistilo em um béquer plástico e o suco obtido (mosto) foi utilizado para a realização das análises químicas: Sólidos Solúveis (SS), Acidez Titulável (AT), pH e relação SS/AT. Os SS foram determinados utilizando refratômetro manual com leitura de 0 a $32^{\circ}$ Brix, com escala de 0,2 ${ }^{\circ}$ Brix. A AT foi realizada por titulação e o resultado expresso em $\mathrm{g} \mathrm{L}^{-1}$ de ácido tartárico (INSTITUTO ADOLFO LUTZ, 1985). O pH foi determinado em potenciômetro digital da mesma amostra antes da titulação.

Os resultados obtidos foram analisados pela regressão polinomial para descrever o comportamento da evolução da maturação de cada cultivar. O sistema computacional utilizado foi o SANEST (ZONTAe MACHADO, 1984).

\section{RESULTADOS E DISCUSSÃO}

A maturidade para o consumo in natura ou para o processamento das uvas é determinada analisando o suco das bagas da amostra quanto aos teores de $\mathrm{pH}$, acidez e sólidos solúveis (CARROL e MARCY, 1982).

As equações de regressão das quatro cultivares de Vitis rotundifolia mostram um aumento significativo no teor de SS durante a maturação das uvas (Figura 1). 


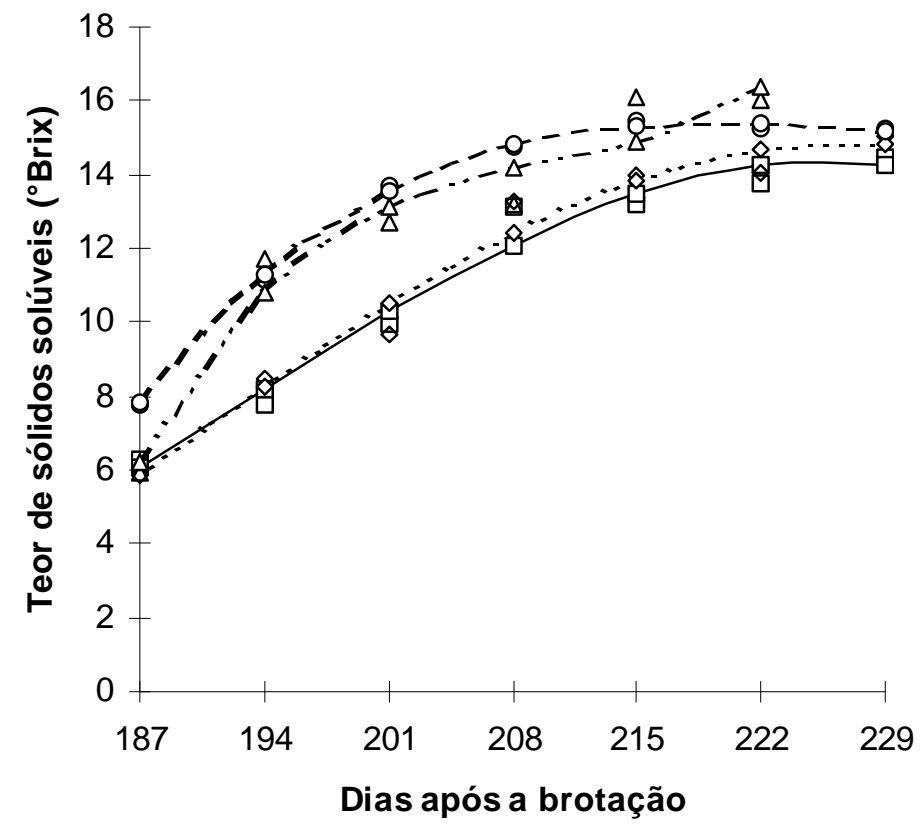

$\square \_$Regale -. - - - . Roanoke - - - - Dixie - - $\Delta-$ - Bontiful

FIGURA 1 - Evolução do teor de sólidos solúveis totais ( ${ }^{\circ}$ Brix) de quatro cultivares de Vitis rotudifolia durante a maturação dos cachos. Regale: $Y=516,99-8,66 x+0,047 x^{2}-0,000082 x^{3}, R^{2}=0,97, C . V .=1,7 \%$; Roanoke: $Y=358,7-6,44 x+0,036 x^{2}-0,000066 x^{3}, R^{2}=0,97, C . V .=1,8 \%$; Dixie: $Y=-1457,33+$ $19,43 x-0,085 x^{2}+0,000124 x^{3}, R^{2}=0,99, C . V .=1,9 \%$, Bontiful: $Y=-4396,58+62,78 x-0,298 x^{2}+$ $0,00047 x^{3}, R^{2}=0,94, C \cdot V .=1,4 \%$.

Inicialmente, aos 187 dias após a brotação, a cultivar Dixie apresentou o maior teor de SS $(7,9$ -Brix) e a cultivar Roanoke o menor teor (5,9 Brix). Aos 222 dias após a brotação, a cultivar Bontiful apresentou o maior teor de SS (16,1 ${ }^{\circ}$ Brix), já praticamente estabilizado em relação a amostra anterior, com 215 dias. Após esse período houve degrana natural da cultivar Bontiful e assim não foi possível continuar a análise desta cultivar.

A cultivar Dixie atingiu o teor máximo de SS aos 215 dias após a brotação (15,5 Brix) e o manteve constante até o final das análises (Figura 1). Para as demais cultivares os valores somente tornaram-se constantes aos 229 dias da brotação.

MULLINS et al. (1994) descreveram que o acúmulo de SS é dependente da fotossíntese e da importação de sacarose das folhas, a qual é posteriormente hidrolisada em glicose e frutose nas bagas. Este acúmulo representa uma significativa mudança no modelo de translocações dos produtos fotossintetizados. No início da maturação, o teor de sólidos solúveis é influenciado pelo alto teor em ácidos orgânicos presentes na baga. Mas, com a evolução da maturação, a participação desses ácidos torna-se menor, e a dos açúcares maior, em decorrência da degradação dos ácidos tartárico e málico e do aumento da síntese de sacarose pela folha.
São consideradas imaturas as uvas que apresentam valores de SS inferiores a 14 ํㅏix (BRASIL, 2002). A Instrução normativa número 1 de $1^{\circ}$ de fevereiro de 2002, do Ministério da Agricultura, Pecuária e Abastecimento, considera que as uvas

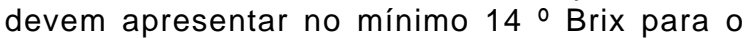
consumo. A cultivar Regale só obteve este teor de SS após 222 dias de brotação, enquanto que as demais conseguiram acumular os açúcares em períodos anteriores.

Observou um aumento no $\mathrm{pH}$ com comportamento similar entre as cultivares tintas e brancas durante a evolução da maturação dos frutos das quatro cultivares de Vitis rotundifolia (Figura 2).

$\mathrm{O} \mathrm{pH}$ das cultivares variou entre 2,7 no início da maturação e 3,6 nas bagas maduras (Figura 2). $\mathrm{O}$ aumento gradual de $\mathrm{pH}$ durante a maturação reflete a formação de sais ácidos às custas do ácido livre (MOTA et al., 2006). A cultivar Dixie apresentou os maiores valores de $\mathrm{pH}$, durante todas as análises e a cultivar Bontiful os menores resultados de $\mathrm{pH}$.

Segundo CARROL e MARCY (1982) devemse colher as bagas quando o $\mathrm{pH}$ estiver variando entre 3,2 a 3,4. Desta forma, a colheita dos frutos pode ser realizada a partir dos 208 dias após a brotação para a cultivar Dixie, que também já apresenta o SS acima de 14 Bix, porém somente a partir de 215 dias após a brotação para a cultivar Bontiful e 229 para as cvs. Regale e Roanoke. 


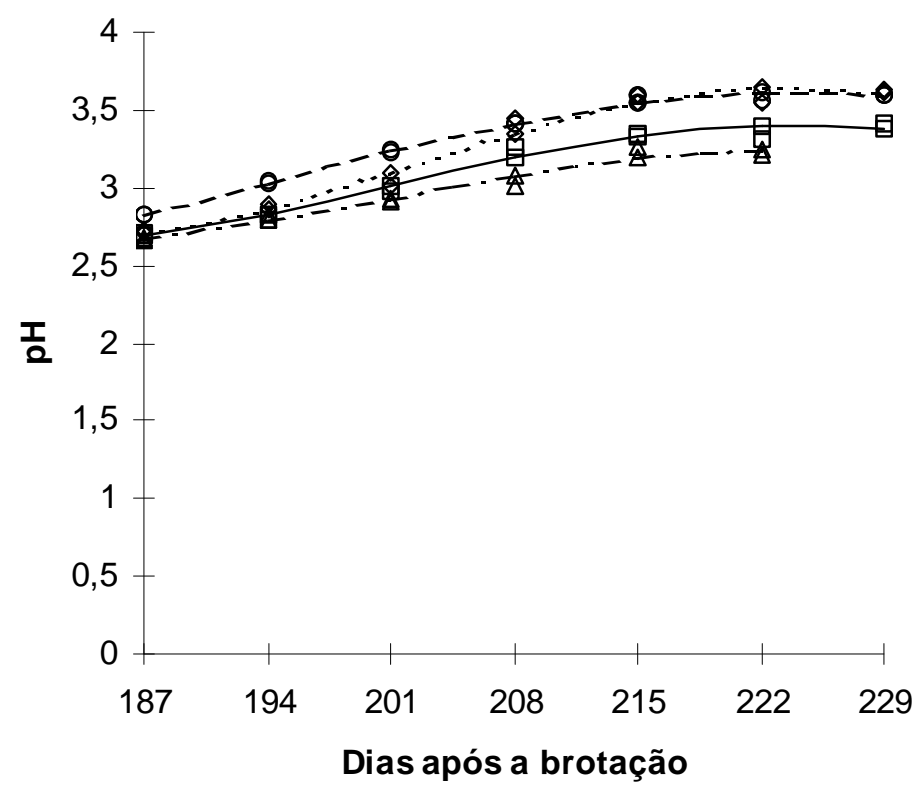

$\square$ Regale ...๑ ... Roanoke - - - - Dixie - - A - - Bontiful

FIGURA 2 - Evolução do $\mathrm{pH}$ de quatro cultivares de Vitis rotudifolia durante a maturação dos cachos. Regale: $Y$ $=118,94-1,78 x+0,009 x^{2}-0,000015 x^{3}, R^{2}=0,96, C . V .=0,8 \%$; Roanoke: $Y=212,62-3,17 x+$ $0,015 x^{2}-0,000026 x^{3}, R^{2}=0,96, C . V .=0,9 \%$; Dixie: $Y=69,95-1,103 x+0,005 x^{2}-0,0000102 x^{3}$, $R^{2}=0,99$, C.V. $=1,5 \%$, Bontiful: $Y=133,08-1,98 x+0,0099 x^{2}-0,000016 x^{3}, R^{2}=0,94$, C.V. $=0,7 \%$

O conteúdo de açúcar e $\mathrm{pH}$ dos frutos aumenta, enquanto que a acidez diminui com o amadurecimento dos frutos (CHITARRA e CHITARRA, 2005). Observou-se que a acidez total titulável decresceu significativamente durante a maturação das uvas. Todas as cultivares apresentaram um comportamento semelhante quanto à AT, diminuindo ao final do ciclo, mas as cultivares diferiram quanto aos valores observados já a partir dos 187 dias após a brotação (Figura 3). A cultivar Dixie apresentou a menor acidez $\left(2,34 \mathrm{~g} \mathrm{~L}^{-1}\right)$ e a cultivar Bontiful a maior $\left(5,08 \mathrm{~g} \mathrm{~L}^{-1}\right)$. As cultivares brancas apresentaram-se menos ácidas do que as cultivares tintas. Segundo CARROL e MARCY (1982), a diminuição na concentração de ácido tartárico parece ser resultado da diluição, com a expansão da baga. Nas bagas em crescimento há um incremento progressivo no conteúdo de ácidos até que chegam a ter aproximadamente a metade do seu tamanho total, pouco antes de iniciar a maturação. A partir da maturação, tanto o conteúdo de tartaratos, quanto o de malatos, diminuem gradualmente (MOTA et al., 2006).

A determinação da acidez tartárica (devida ao ácido tartárico) somada à determinação dos açúcares, fornece uma boa medida do estádio de maturação da uva.

Em função da evolução inversa dos fatores que influem nas variáveis relacionadas ao açúcar e à acidez, a relação SS/AT aumentou de forma significativa durante a maturação. Essa relação foi de 0,51 no início da maturação e de 6,88 na maturação para cultivar Dixie, a qual apresentou um aumento médio de 0,187 dia-1 (Figura 4). Ao final do período amostral, as cultivares brancas apresentaram as maiores relações SS/AT e as cultivares tintas as menores.

A relação SS/AT é uma das variáveis que podem caracterizar as cultivares numa determinada região. No entanto, a utilização dessa relação como índice de maturação da uva deve ser feita com cautela, pois aumentos na concentração de açúcar nem sempre correspondem à igual redução da acidez total (MANFROI et al., 2004).

Pode-se verificar que a cultivar Dixie apresentou maiores valores médios para os teores de SS e menores para a AT, o que resultou em uma relação SS/AT muito superior às demais cultivares. Essa relação é um importante atributo qualitativo, uma vez que indica o sabor inerente ao produto, o qual é resultado da contribuição dos componentes responsáveis pela acidez e doçura (CHITARRA e CHITARRA, 2005).

A característica mais importante para definir o ponto ideal de colheita foi à estabilidade dos valores do teor de sólidos solúveis, $\mathrm{pH}$, acidez e relação SS/AT. As cvs. Bontiful e Dixie apresentaram como época mais indicada para a colheita a metade do mês de abril (215 dias após a brotação), enquanto que para as cvs. Regale e Roanoke o período ideal ocorreu no final do mês de abril, ou seja, 229 dias após a brotação. 


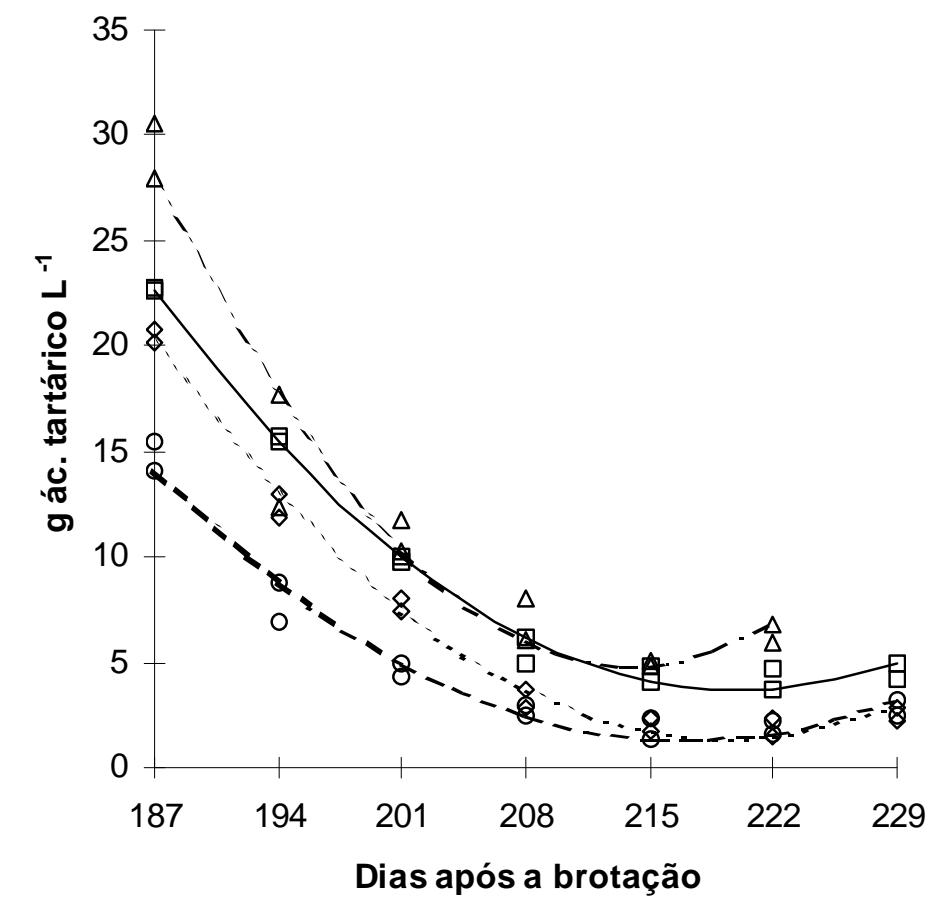

$\square$ - Regale - . - - . - Roanoke - - - - Dixie - - $\Delta$ - - Bontiful

FIGURA 3 - Evolução da acidez, expressa em g ácido tartárico $\mathrm{L}^{-1}$ de quatro cultivares de Vitis rotudifolia durante a maturação dos cachos. Regale: $Y=838,83-7,58 x+0,017 x^{2}, R^{2}=0,98, C . V .=3,24 \%$; Roanoke: $Y$ $=850,28-7,729 x+0,017 x^{2}, R^{2}=0,98, C \cdot V .=7,3 \% ;$ Dixie: $Y=664,18-6,1 x+0,014 x^{2}, R^{2}=0,94$, C.V. $=8,9 \%$, Bontiful: $Y=1436,74-13,36 x+0,0311 x^{2}, R^{2}=0,90$, C.V. $=3,5 \%$.

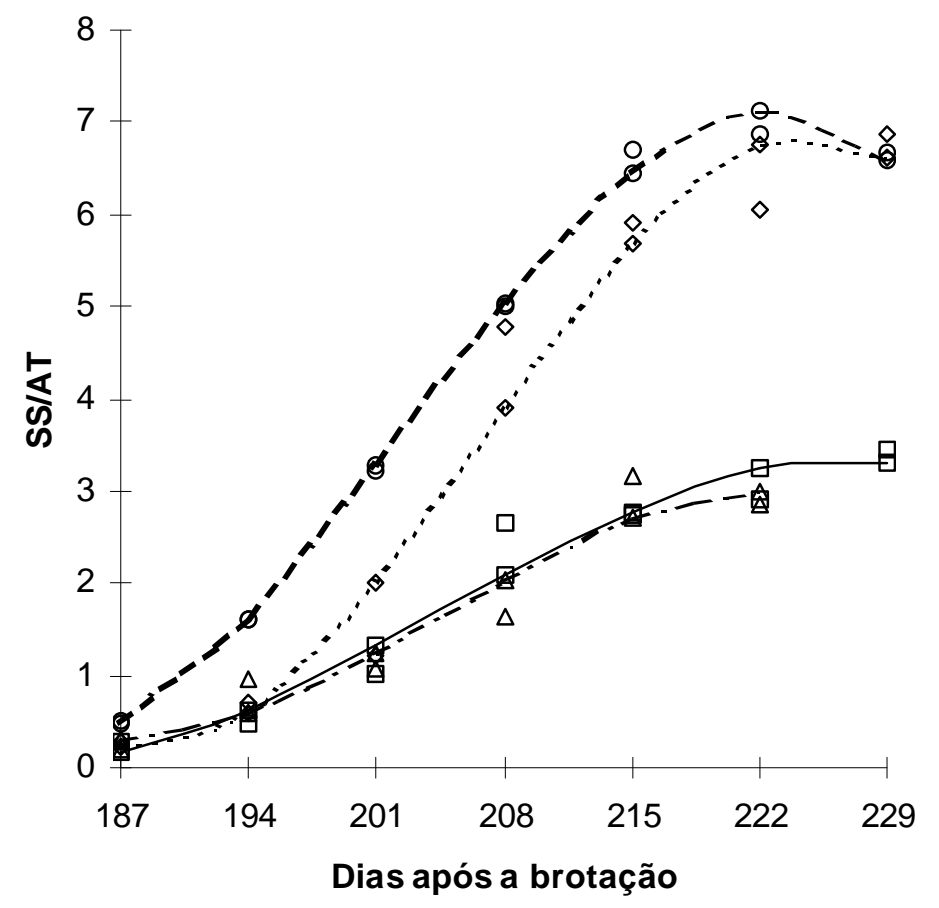

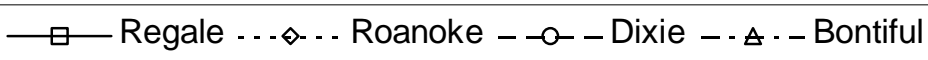

FIGURA 4 - Evolução da relação SS/AT de quatro cultivares de Vitis rotudifolia durante a maturação dos cachos. Regale: $Y=633.67-9,48 x+0,0469 x^{2}-0,000076 x^{3}, R^{2}=0,94, C . V .=6,8 \%$; Roanoke: $Y=2413,6-$ $35,53 x+0,173 x^{2}-0,00027 x^{3}, R^{2}=0,95$, C.V. $=8,0 \%$; Dixie: $Y=1679,27-25,32 x+0,126 x^{2}-0,0002 x^{3}$, $R^{2}=0,99$, C.V. $=18,73 \%$, Bontiful: $Y=1051,06-15,61 x+0,076 x^{2}-0,00012 x^{3}, R^{2}=0,91, C . V .=12,4 \%$. 


\section{CONCLUSÕES}

Concluí-se que a data ideal de colheita em Pinhais-PR, para a cvs. Bontiful e Dixie ocorre a partir da metade do mês de abril, com 215 dias após a brotação; já para as cvs. Regale e Roanoke ocorre no final do mês de abril, com 229 dias após a brotação; a cultivar Dixie apresentou o maior teor de sólidos solúveis, maior $\mathrm{pH}$, maior relação SS/AT e menor acidez durante a maturação dos frutos; a cultivar Bontiful apresentou a maior acidez, o menor $\mathrm{pH}$ e relação SS/AT.

\section{AGRADECIMENTOS}

Os autores agradecem a Marcos Cesar Degan Sachi pelo apoio na realização das análises laboratoriais.

\section{REFERÊNCIAS}

1. BOTTON, M.; SCHUCK, E.; SORIA, S. de J.; HICKEL, E.R. Manejo de pragas na cultura da videira. Bento Gonçalves: Embrapa Uva e Vinho, 2004. Disponível em: <http://www.cnpuv.embrapa.br/publica/sprod/viticultura/perola.html> Acesso em: 13 abr. 2007.

2. BRASIL. Ministério da Agricultura, Pecuária e Abastecimento. Instrução normativa ํㅡ 1 de 1 de fevereiro de 2002. Regulamento técnico de identidade e de qualidade para a classificação da uva rústica. Diário Oficial da República Federativa do Brasil, 4 fev. 2002, Seção I.

3. CARROL, D.E.; MARCY, J.E. Chemical and physical changes during maturation of muscadine grapes (Vitis rotundifolia). American Journal of Enology and Viticulture, v. 33, n. 3, p. 168-172, 1982.

4. CHITARA, M.I.F.; CHITARRA, A.B. Pós-colheita de frutas e hortaliças: fisiologia e manuseio. Lavras: Editora de Universidade Federal de Lavras, 2005. 785 p.

5. GIOVANNINI, E. Uva agroecológica. Porto Alegre: Renascença, 2001. $136 \mathrm{p}$.

6. GUERRA, C.C. Colheita e destino da produção. In: KUHN, G.B. Uva para processamento. Produção. Bento Gonçalves: Embrapa Uva e Vinho; Brasília: Embrapa Informação Tecnológica. 2003. p. 123-125.

7. HIDALGO, L. Tratado de viticultura general. Madrid: Mundi-Prensa, 1993. $983 \mathrm{p}$.

8. HOFFMANN, A.; SEBBEN, S.S. SEMINÁRIO BRASILEIRO SOBRE PEQUENAS FRUTAS, 1., 2003, Vacaria. Anais. Bento Gonçalves: Embrapa Uva e Vinho, 2003. 60 p. (Embrapa Uva e Vinho. Documentos, 37).

9. INSTITUTO ADOLFO LUTZ. Normas analíticas do Instituto Adolfo Lutz: métodos químicos e físicos para análise dos alimentos. 3. ed. São Paulo: Instituto Adolfo Lutz, 1985. v. 1. 371 p.

10. MANFROI, L.; MIELE, A.; RIZZON, L.A.; BARRADAS, C.I.N.; SOUZA, P.V. de. Evolução da maturação da uva Cabernet Franc conduzida no sistema lira aberta. Ciência e Agrotecnologia, v. 28, n. 2, p. 306-313, 2004.

11. MANICA, I.; POMMER, C.V. Uva: do plantio a produção, pós-colheita e mercado. Porto Alegre: Cinco Continentes, 2006. $185 \mathrm{p}$.

12. MOTA, R.V.; REGINA, M. de A.; AMORIM, D.A.; FÁVERO, A.C. Fatores que afetam a maturação e a qualidade da uva para vinificação. Informe Agropecuário, v. 27, n. 234, p. 56-64, 2006.

13. MULLINS, M.G.; BOUQUET, A.; WILLIANS, L.E. Biology of the grapevine. New York: University of Cambridge, 1994. 239 p.

14. PASTRANA-BONILLA, E.; AKOH, C.C.; SELLAPPAN, S.; KREWER, G. Phenolic content and antioxidant capacity of Muscadinegrapes. Journal of Agricultural and Food Chemistry, v. 51, n. 18, p. 5497-5503, 2003.

15. SOUSA, J.S.I. de. Uvas para o Brasil. 2. ed. Piracicaba : FEALQ, 1996. 791 p.

16. ZONTA, E.P.; MACHADO, A.A. SANEST: Sistema de análise estatística para microcomputadores. Pelotas: UFPel, 1984.

Recebido em 29/11/2007 Aceito em 11/03/2008 
